\title{
PRESCRIPTION DRUG USER FEES: IMPROVEMENT AT A PRICE?
}

User fees are here to stay for another five years. Their first ten years have been a success, but

is this diverting our attention away from some of the wider issues in drug development?

Taxation on the benefit principle, the idea that those that benefit from a service should be the ones to pay for it, is well accepted. Although we might balk at the level of fee that accompanies an application for a driving licence, the idea of paying something for the service you are getting seems fair enough. The principle has its limits, however, and there are areas of life in which we prefer to keep the separation of the service provider and its recipients more obvious. Should, for instance, motorists pay the cop for writing out the speeding ticket? Probably not.

Somewhere along the fuzzy line that divides appropriate from inappropriate benefit taxation lies the Prescription Drug User Fee Act (PDUFA) of 1992. Enacted in response to lengthening drug-approval times, the act linked the payment of fees by drug developers to increases in the efficiency of the FDA review and approval process for new drugs and biopharmaceuticals. Having been recently re-authorized by Congress for a third fiveyear term, the act, in a slightly modified form known as PDUFA III, takes effect on 1 October 2002. Although widely praised by pharmaceutical companies and US regulators for having reduced FDA review times substantially, the act is at best only a partial solution to the industry's regulatory woes, and bears close inspection.

The Food, Drug and Cosmetic Act of 1962 set a target for the FDA to approve or deny all New Drug Applications (NDAs) within 180 days, but by the 1980s, the average time taken for review and approval was running at $\sim 2.5$ years. The 1992 PDUFA provided that monies paid by industry in the form of fees would be channelled into increasing the speed and efficiency of review procedures at the FDA. These user fees are used exclusively for new drug and biopharmaceutical reviews and fund $\sim 50 \%$ of the FDA's drug-review procedures at present. The current target is to reach decisions on all priority-rated applications (for products proposed to deliver substantial therapeutic improvements) within six months, and all standard applications within ten months.
The latest data from the Tufts Center for the Study of Drug Development show that priority-rated drugs and biopharmaceuticals are now being approved within 7-8 months, whereas standard applications take between $1.5-2$ years. This acceleration of the review process has been accompanied by an increase in the probability of approval, which has risen from $\sim 60 \%$ to $80 \%$ during the ten years of the programme, a rise attributed to increased communication between regulatory authorities and industry during drug development. Although the few recent high-profile drug withdrawals have led critics to suggest that faster approvals are leading to more post-marketing problems, the numbers indicate an even level of drug withdrawals before and after the advent of PDUFA. So, increased efficiencies with no compromise over safety. Sounds good.

Introducing efficient decision making into the new drug and biopharmaceutical application procedure is, however, fixing only the final stage in the pipeline. Although user fees have meant that the resources for review activities at the FDA have been growing over the past ten years, funding for all other activities at the FDA has actually been decreasing since 1992. User fees account for just $13 \%$ of total FDA revenue, and areas such as post-marketing surveillance are now chronically underfunded parts of the FDA's remit. Could it be that the much-vaunted success of the PDUFA has the effect of deflecting attention away from some of the shortfalls elsewhere in the agency?

There are those who argue that we need a far more radical overhaul of drug regulation to bring about the dramatic time savings that are so urgently desired, but for now, the PDUFA is with us for another five years. Meanwhile, there will be plenty who object to the seemingly 'too-close' alliance of the drug producers and the agency that polices their actions. Even the most committed of advocates admits that the PDUFA creates opportunities for conflicts of interest, even is these go by unused. 